\section{TeChNology Transfer Is Part OF OUR HERITAGE}

I

IN THE SPRING OF 1861 Matthew Fontaine Maury, whom many of us know as "The Pathfinder of the Seas" and the first Oceanographer of the U.S. Navy, had something of a change of heart and, perhaps as a reflection of the rebel spirit of many oceanographers, aligned himself with the fledgling Navy of the Confederate States of America. In his new commission, Captain Maury served as the Father of the Modern Torpedo, since his charge (pun intended) as an officer of the secessionist Navy was to design and build a new type of underwater weaponry, the descendants of which we now call mines. Maury's educational background and his advances in ocean science gave him the skills to exploit the marine environment in what, arguably, was not a particularly constructive venue. Nevertheless, he recognized that the only way he could achieve his technological and scientific goals was through the transfer of technologies from other fields. His earliest mine designs were mechanical in nature and were highly unreliable. Maury acknowledged that the relatively young science of electricity might provide him with advanced capabilities for underwater applications. His insight proved excellent. He dispatched his agents to New York to obtain that very rare and extremely modern technological component that he needed: insulated wire. Were it not for the fact that his agents were caught and sentenced for espionage, Maury may well have made the breakthrough early in the Civil War to send the South on to victory. Arguably, Matthew Fontaine Maury's efforts in the 1860's were not of a truly oceanographic nature, but they clearly embodied the spirit of technology transfer that is still central to basic research in oceanography.

Advancements in biomedicine, solid state physics, and telecommunications, just to name a few, are occurring at an unprecedented pace. This, coupled with the nature of the oceans as a dynamic, conducting, variably transparent (optically and acoustically). nutrient rich medium, suggests that studies of the marine environment lend themselves well to transfer of technology. This special focus issue of Oceanography is a collection of papers exemplifying the breadth of technology transfer into the study of the organisms and processes that define the ocean and the marine atmosphere.

Interestingly, as disparate as such topics as molecular biological oceanography and remotely piloted vehicles might seem, there are some common themes to the papers contained herein. It is evident that the transfer of technology into ocean sciences is aimed at such central issues as increased data density, improved real-time remote sensing capability, and "truer" synopticity. Fiber-optic probes allow for higher spatial resolution and faster data throughout; mammal-borne satellite tracking tags show us biological populations on time and space scales previously unattainable; networks of autonomous underwater vehicles may allow us to envelop areas of the ocean, in a manner not unlike cellular telephone systems, and on it goes.

Do these transfers of technology really improve the science? Well, the answer lies in the results which are just coming to the fore. More importantly, by embodying the philosophy of technology transfer, we invoke a ceratin "hybrid vigor" into the ocean sciences, an approach which is, as all biologists know, vital to the preservation of the community.

-Richard W. Spinrad,

Office of Naval Research Special Issue Guest Editor

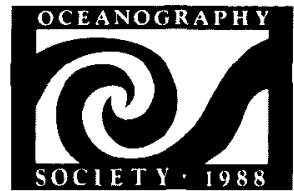

THE OCEANOGRAPHY SOCIETY

1124 Wivenhoe Way Virginia Beach, VA 23454 USA (804) 496-8958; fax: (804) 496-8960 omnet: OCEANOGRAPHY.SOCIETY

\section{OFFICERS}

Arnold L Gordon, President Margaret Leinen, President-Elect Melbourne G. Briscoe, Secretary William M. Dunstan, Treasurer

COUNSELORS Richard T. Barber Stephen E. Calvert

Tommy D. Dickey

Richard Jahnke

Kevin D. Leaman

Charles A. Nittrouer, ex officio

\section{EXECUTIVE DIRECTOR} Judi Rhodes

CORPORATE/INSTITUTIONAL SPONSORS Aanderaa Instruments, Inc., Woburn, MA, USA Chishitsu Chosa-Jo, Ibaraki, Japan GE Astro Space Division Princeton, NJ, USA John G. Shedd Aquarium, Chicago, IL, USA Monterey Bay Aquarium Research Institute, Pacific Grove, CA, USA

National Marine Fisheries Service, Sitver Spring, MD, USA

Ober, Kaler, Grimes \& Shriver. Washington, DC, USA

RD instruments, San Diego, CA, USA

Scripps Institution of Oceanography, La Jolla, CA, USA

Woods Hole Oceanographic Institution, Woods Hole, MA, USA

\section{OCEANOGRAPHY}

CO-EDITORS

Larry $P$. Atkinson

Center for Coastal Physical Oceanography

Old Dominion University Crittenton Hall

Nortolk, VA 23529

(516) 683-5558; L.ATKINSON

Internet: atkinson@ccpo.odu.edu

Connie Sancetta

National Science Foundation

Ocean Sciences Division 4201 Wilson Blvd.

Arlington, VA 22203

(703) 306-1586; C. SANCETTA

Internet: csancett@ note.nst.gov

ASSOCIATE EDITORS

James $W$. Ammerman

Department of Oceanography

Texas A\&M University

College Station, TX 77843 USA

(409) 845-5105; J.AMMERMAN

Gregory J. Brunskill

Australian Institute of Marine Science

PMB No. 3. Townsville, M.C.

Queensiand 4810, Australia

(77)789211; G.BRUNSKILL 